\title{
FEATURES OF RECONDITIONING STEEL DRILL BIT WATERCOURSE
}

\author{
B.V. STEFANIV, V.F. KHORUNOV, O.M. SABADASH, S.V. MAKSYMOVA and V.V. VORONOV \\ E.O. Paton Electric Welding Institute, NASU
}

11 Bozhenko Str., 03680, Kiev, Ukraine. E-mail: office@paton.kiev.ua

\begin{abstract}
Peculiarities of defects in worn steel drill bit developing in service at gas well drilling are considered, damage at anomalous wear of water course moving element is described; methods to prepare the worn section for its reconditioning by welding and protective coating deposition are tried out. Special attention is given to analysis of microstructure and chemical inhomogeneity of joint line of steel $40 \mathrm{Kh}+$ protective wear-resistant coating, stainless steel $08 \mathrm{Kh} 18 \mathrm{~N} 10 \mathrm{~T}$ + protective wear-resistant coating, stainless steel $08 \mathrm{Kh} 18 \mathrm{~N} 10 \mathrm{~T}+$ steel $40 \mathrm{Kh}+$ protective wear-resistant coating; deposited layer microhardness is determined. It is shown that deposition of wear-resistant coating by surfacing provides effective protection from erosive and abrasive wear of bits at drilling of medium and hard rock. Proceeding from the derived data, technology of reconditioning the water course moving element of this drill bit was developed. The drill bit has successfully passed trials at drilling of gas and oil wells in soft, medium-hard and hard rocks in the company «Representative Office USEIS SA» in Poltava region. 2 Ref., 3 Tables, 5 Figures.
\end{abstract}

$\boldsymbol{K} \boldsymbol{e} \boldsymbol{y} \boldsymbol{w} \boldsymbol{o r d} \boldsymbol{s}:$ drill bits, superhard materials, protective coating, surfacing, wear resistance, welding, microhardness, strength, reconditioning of working elements

In drilling of gas and oil wells working elements of bodies of steel bits and heads are exposed to intensive abrasive, erosive, corrosive, cavitation, hydroabrasive and impact wear, resulting in the change of the initial shape and lowering of technico-economic characteristics of drill tools, that is why increase of service life of working elements of steel and matrix bodies of local and foreign drill bits and heads in an urgent task for Ukraine. Reconditioning, increasing the effectiveness of drill bit and head application and lowering the cost of development of problem fields, is an important reserve for extension of their service life.

Development of technological processes of drill tool repair is progressing, and at this moment the enterprises and companies in Ukraine and abroad offer different methods of reconditioning the worn working elements. In 20102012 studies of the degrees of wear and peculiarities of defects of diamond-insert cutters (DIC) of steel and matrix drill bits, applied in drilling of gas and oil wells in rocks, were performed under «Resours» Program. These studies were the basis to compile tables of DIC wear and defects in keeping with the classification of International Association of Drilling Contractors (IADC), depending on rock physico-mechanical characteristics [1], and develop the technology of repair of steel and matrix drill bits of different typesizes with DIC [2].
The objective of this work is evaluation of the peculiarities of watercourse damage as a result of anomalous wear of steel drill bit body with protective coatings and determination of its repairability criteria for subsequent reconditioning of the working element.

Objects of study are tools for rotation drilling method, namely drill bits and heads. Foreign drilling tools are mainly made of B25 and B35 hard alloys produced by Sandvik Coromat, Sweden (local analogs are VK6 and VK8 alloys) and are fitted with polycrystalline diamond cutters XT, HCR, HOT, SQC, GDC, etc., manufactured by leading world companies, such as Genesis, Smith Bits, Element Six. Drilling tool working elements are protected by surface coatings having high tribological properties under the conditions of hydropabrasive wear.

For reconditioning worn drill bits it was necessary to develop the technological procedure, including:

- drill bit wear analysis by IADC classification;

- defect list of worn drill bit working elements;

- machining of working element defective areas;

- special preparation of areas on damaged defective surfaces;

- process of restoration of initial shape of working elements of drill bit body by welding;

- process of restoration of working element protective coatings with preservation of initial drill bit dimensions. 
Features of reconditioning drill bits with anomalous wear of working element are demonstrated in the case of repair of watercourse in steel drill bit of $215.9 \mathrm{~mm}$ diameter manufactured by Smith Bits, USA. Working elements of such a drill bit at rotation drilling of the well, being exposed to axial load at rock breaking up, move at different speed along bore hole bottom and are subjected to anomalous wear. In addition, removal of fracture products is performed by drilling water at high pressure $(1500 \mathrm{MPa})$ that creates an additional risk of fracture of drill bit watercourses. Evaluation of drill bit condition after driving through $1000 \mathrm{~m}$ revealed significant damage of the opening of steel body watercourse with strengthening protective coating - tearing out of thread bushing made of VK8 alloy ( Figure 1), to which the hard alloy nozzle was attached, and considerable distortion of watercourse shape. The cause for tearing out of the bushing with nozzle from drill bit body, in our opinion, was violation of technology of watercourse thread bushing manufacturing. Final evaluation of drill bit body by IADC classification was as follows: 37 LN N X (LN, NO) PR «repairable».

During watercourse reconditioning studies were performed on selection of a material that would correspond to all the physico-chemical properties of drill bit body metal. To achieve this goal, preliminary work results were used to develop a new design of transition bushing with the respective thread from corrosion-resistant steel $08 \mathrm{Kh} 18 \mathrm{~N} 10 \mathrm{~T}$ and technology of restoration of damaged watercourse. Welding and surfacing were optimized on mock-up samples: steel $40 \mathrm{Kh}+$ protective wear-resistant coating; stainless steel $08 \mathrm{Kh} 18 \mathrm{~N} 10 \mathrm{~T}+$ protective wear-resistant coating; stainless steel $08 \mathrm{Kh} 18 \mathrm{~N} 10 \mathrm{~T}+$ steel $40 \mathrm{Kh}+$ deposited metal.

Nonconsumable-electrode manual argon-arc welding with $1 \mathrm{~mm}$ filler wire $12 \mathrm{Kh} 18 \mathrm{~N} 10 \mathrm{~T}$ was selected for experiments. One of the most effective technologies of drill bit reconditioning is the low-cost and technologically acceptable process of arc surfacing. Protective coating was deposited on mock-up samples with application of inverter system «Korall-300» and TeroCote $7888 \mathrm{~T}$ filler cord of $5 \mathrm{~mm}$ diameter with $1.2 \mathrm{~mm}$ core, manufactured by Castolin Eutectic. Surfacing was performed in optimum modes with the lowest heat input: $I=80-100 \mathrm{~A}, U=10-12 \mathrm{~V}$. Deposit thickness was $2-3 \mathrm{~mm}$.

Metallographic examination of welded and surfaced samples was performed in optical microscope MIM-8M and scanning electron micro-

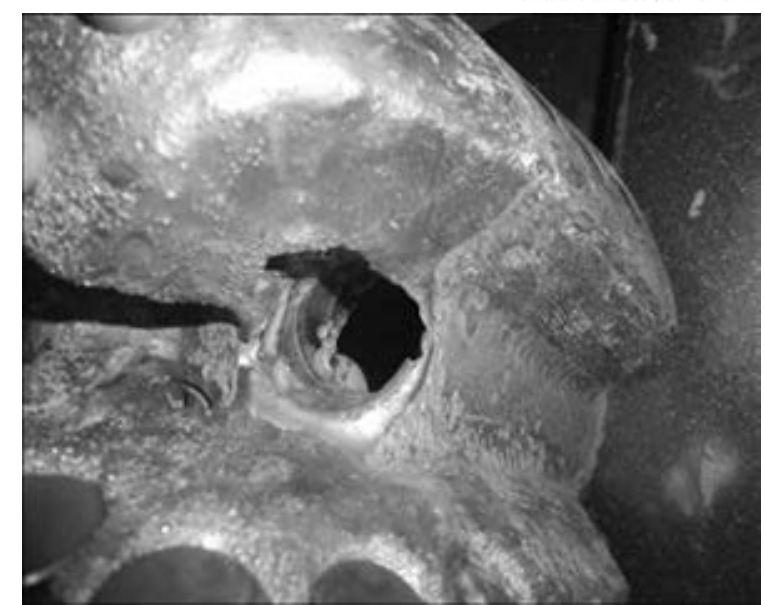

Figure 1. Appearance of wear of working element of steel body watercourse with strengthening protective coating

scope Tescan Mira 3 LMU. Vickers microhardness of the deposited layer was determined in LECO hardness meter (0.01-2 kg load).

Microsections with wear-resistant coating TeroCote $7888 \mathrm{~T}$, deposited on plates of steel $40 \mathrm{Kh}$ and stainless steel $08 \mathrm{Kh} 18 \mathrm{~N} 10 \mathrm{~T}$, were used for investigations.

Product wear-resistance is affected by a number of parameters: composition, structural components, deposited metal hardness. For instance, hardness of protective coating surface layer is strongly affected by distribution of hard particles of tungsten carbide in the deposited layer volume. Naturally, functional effectiveness of the deposited coating will rise with increase of the amount of tungsten carbide of high microhardness. TeroCote $7888 \mathrm{~T}$ is a highly-effective wear-resistant material in the form of a flexible cord, which consists of nickel-chromium wire core, coated by an elastic binder, containing a mixture of irregular-shaped carbides and a powder-like nickel alloy. TeroCote $7888 \mathrm{~T}$ coating is extremely hard and consists of a dense mass of ultrahard tungsten carbide particles, integrated into a viscous nickelchromium matrix.

TeroCote $7888 \mathrm{~T}$ coating, deposited on steel $40 \mathrm{Kh}$, is characterized by cast heterogeneous structure (Figure 2, a). Rather coarse carbide particles of up to $500 \mu \mathrm{m}$ length are concentrated in the deposit lower zone. Needle-like dispersed precipitates of the light phase based on tungsten, which contain chromium, iron and nickel, are revealed in the matrix of the deposit based on nickel $(33.7 \%)$, containing iron $(26.80 \%)$, tungsten $(25.95 \%)$ and other elements (Table 1$)$.

Unlike lower zone structure, metal structure of the deposit upper zone does not contain any coarse carbides (Figure 2, $b$ ). Microhardness of the deposit upper zone is 4460-4830 $\mathrm{MPa}$ that is somewhat lower than that of the lower zone 
INDUSTRIAL

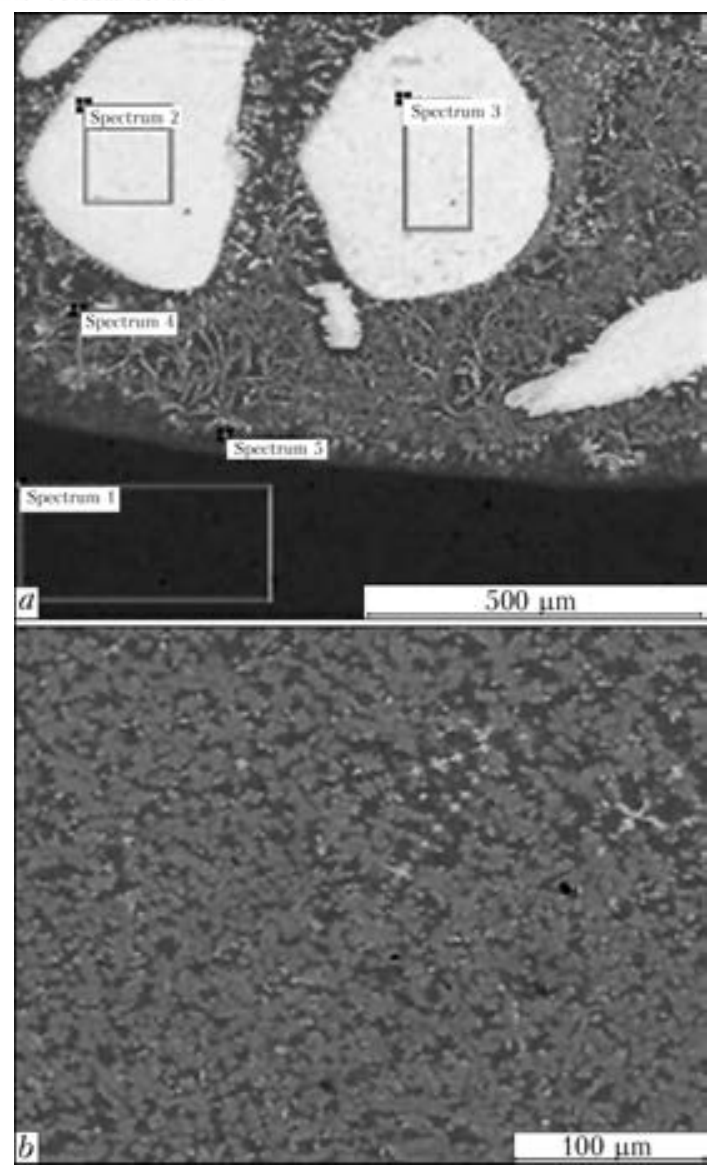

Figure 2. Microstructure of TeroCote $7888 \mathrm{~T}$ deposited metal on substrate of steel $40 \mathrm{Kh}(a)$ and its upper zone $(b)$
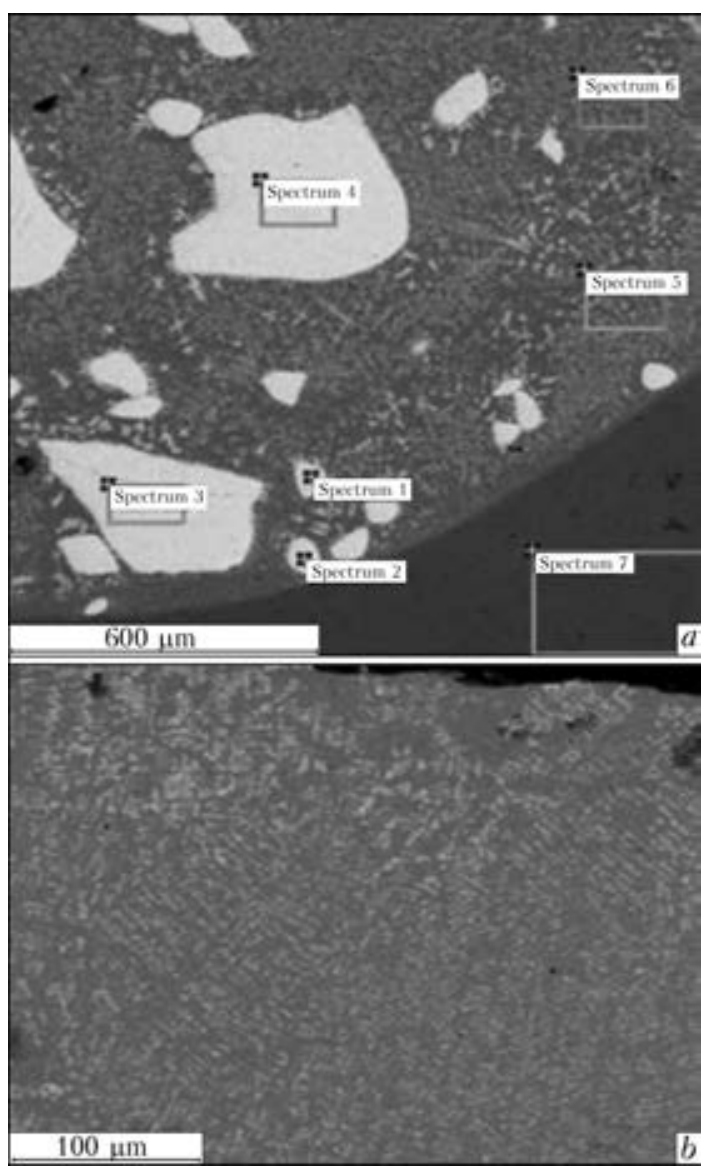

Figure 3. Microstructure of lower $(a)$ and upper $(b)$ zone of TeroCote $7888 \mathrm{~T}$ deposited metal on substrate of 08KN18N10T steel

Table 1. Composition of TeroCote $7888 \mathrm{~T}$ deposited metal on $40 \mathrm{Kh}$ steel substrate, wt.\%

\begin{tabular}{||c|c|c|c|c|c|c|c|c||}
\hline $\begin{array}{c}\text { Spectrum } \\
\text { number }\end{array}$ & $\mathrm{C}$ & $\mathrm{O}$ & $\mathrm{Si}$ & $\mathrm{Cr}$ & $\mathrm{Mn}$ & $\mathrm{Fe}$ & $\mathrm{Ni}$ & $\mathrm{W}$ \\
\hline 1 & 6.64 & - & 0.30 & 3.59 & 0.51 & 88.96 & - & - \\
\hline 2 & 12.86 & 1.15 & - & - & - & - & - & 85.99 \\
\hline 3 & 11.80 & 1.03 & - & - & - & - & - & 87.17 \\
\hline 4 & 6.25 & - & - & 7.29 & - & 26.80 & 33.70 & 25.95 \\
\hline 5 & 6.47 & - & - & 9.38 & - & 41.13 & 30.99 & 12.4 \\
\hline
\end{tabular}

Table 2. Composition of TeroCote $7888 \mathrm{~T}$ deposited metal on $08 \mathrm{Kh} 18 \mathrm{~N} 10 \mathrm{~T}$ steel substrate, wt.\%

\begin{tabular}{||c|c|c|c|c|c|c|c|c|c||}
\hline \hline $\begin{array}{c}\text { Spectrum } \\
\text { number }\end{array}$ & $\mathrm{C}$ & $\mathrm{O}$ & $\mathrm{Si}$ & $\mathrm{Ti}$ & $\mathrm{Cr}$ & $\mathrm{Mn}$ & $\mathrm{Fe}$ & $\mathrm{Ni}$ & $\mathrm{W}$ \\
\hline 1 & 12.02 & 0.79 & - & - & - & - & - & - & 87.18 \\
\hline 2 & 12.31 & - & - & - & - & - & - & - & 87.69 \\
\hline 3 & 12.18 & - & - & - & - & - & - & - & 87.82 \\
\hline 4 & 12.72 & 1.33 & - & - & - & - & - & - & 85.95 \\
\hline 5 & 6.96 & - & - & - & 13.91 & - & 23.25 & 35.72 & 20.17 \\
\hline 6 & 6.65 & - & - & - & 15.25 & - & 24.01 & 34.86 & 19.23 \\
\hline 7 & 5.42 & - & 0.53 & 0.37 & 24.13 & 0.70 & 54.35 & 14.51 & - \\
\hline
\end{tabular}


Table 3. Composition of deposited metal in the joint of $08 \mathrm{Kh} 18 \mathrm{~N} 10 \mathrm{~T}+40 \mathrm{Kh}+$ TeroCote $7888 \mathrm{~T}$, wt.\%

\begin{tabular}{||c|c|c|c|c|c|c|c||}
\hline $\begin{array}{c}\text { Spectrum } \\
\text { number }\end{array}$ & $\mathrm{C}$ & $\mathrm{Si}$ & $\mathrm{Cr}$ & $\mathrm{Mn}$ & $\mathrm{Fe}$ & $\mathrm{Ni}$ & $\mathrm{W}$ \\
\hline 1 & 5.51 & - & 10.23 & - & 39.12 & 37.35 & 7.79 \\
\hline 2 & 6.50 & 0.33 & 4.22 & 0.57 & 88.38 & - & - \\
\hline 3 & 6.60 & - & 12.11 & - & 31.27 & 35.33 & 14.69 \\
\hline 4 & 12.16 & - & - & - & - & - & 87.84 \\
\hline 5 & 11.31 & - & - & - & - & - & 88.69 \\
\hline
\end{tabular}

(4460-5420 MPa). Note that carbide phase microhardness is stable and is equal to $18540 \mathrm{MPa}$.

The metal of TeroCote $7888 \mathrm{~T}$ deposit on stainless steel $08 \mathrm{Kh} 18 \mathrm{~N} 10 \mathrm{~T}$ steel also contains coarse tungsten carbides in the lower zone (Figure 3, $a$, Table 2).

Metal of deposit upper zone contains less carbides, and in some sections they are completely absent (Figure 3, b). Microhardness of the deposit matrix in upper zone decreases to 3510 $3760 \mathrm{MPa}$, and in lower zone - to 3360$4210 \mathrm{MPa}$.

Metallographic and X-ray microprobe studies of the joint of $08 \mathrm{Kh} 18 \mathrm{~N} 10 \mathrm{~T}$ steel + steel $40 \mathrm{Kh}+$ deposited metal showed that a joint of TeroCote $7888 \mathrm{~T}$ deposited material + steel $40 \mathrm{Kh}$ formed as a result of surfacing. Deposited metal microstructure consists of tungsten carbides and matrix based on nickel of a complex composition ( $\mathrm{Ta}$ ble 3). As is seen in the previous variants, tungsten carbides are contained predominantly in deposit lower zone (Figure 4, $a$ ) and are absent in its upper zone (Figure 4,b). Slight porosity is observed in all the deposits.

Obtained structure of deposited metal ensures high microhardness of the carbide phase and extremely effective protection from erosive and
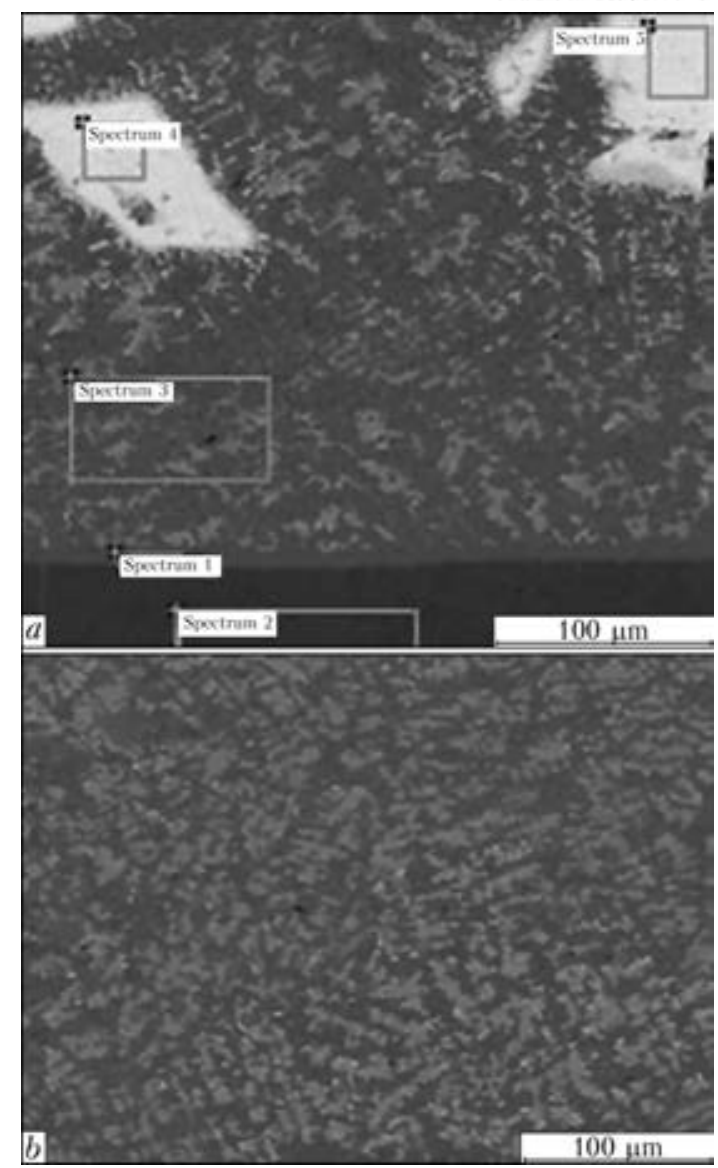

Figure 4. Microstructure of lower $(a)$ and upper $(b)$ zone of deposited metal in the joint of $08 \mathrm{Kh} 18 \mathrm{~N} 10 \mathrm{~T}+40 \mathrm{Kh}+$ TeroCote $7888 \mathrm{~T}$

abrasive wear at drilling of medium and hard rocks. Applied method to improve wear resistance with TeroCote $7888 \mathrm{~T}$ filler cord allows a considerable (2-3 times) extension of service life of working elements of drill bit bodies, operating under the conditions of corrosive-abrasive wear.

Obtained results were used at reconditioning of watercourse working element on a worn body of integral steel diamond drill bit of $215.9 \mathrm{~mm}$

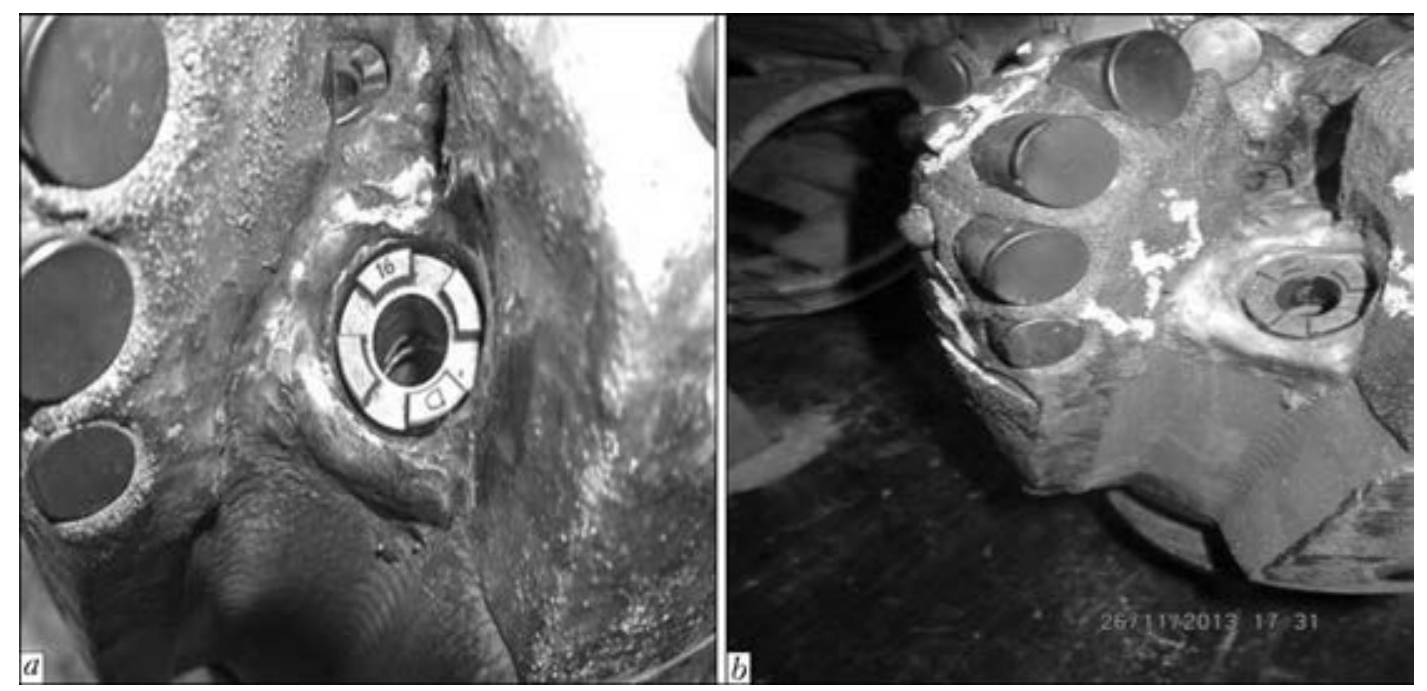

Figure 5. Appearance of reconditioned watercourse before $(a)$ and after $(b)$ testing 
diameter. After machining the damaged opening of the watercourse a bushing from stainless steel 08Kh18N10T was manufactured and mounted in the body opening with the specified angle of inclination. To join the bushing to drill bit body, welding with small heat input was used in the optimum modes of $I=80-120$ A, $U=10-12 \mathrm{~V}$, in order to lower the residual stress level in the deposited layers. Welding was performed with $1 \mathrm{~mm}$ filler wire $12 \mathrm{Kh} 18 \mathrm{~N} 10 \mathrm{~T}$. TeroCote $7888 \mathrm{~T}$ cord was used for deposition of the protective wear-resistant coating in the following mode: $I=$ 100-120 A, $U=10-12 \mathrm{~V}$.

Drilling of Runovshchina gas wells (Poltava region) was performed for trying out the reconditioned drill bit (Figure 5,a). Drill bit $8^{1 / 2^{\prime \prime}}$ SI519 BPX SD0502 was tested in well \#101 in the ranges of 533-542, 549-734, 744-886 $\mathrm{m}$ and in well \#110 in the range of $1890-2679 \mathrm{~m}\left(\mathrm{Fi}^{-}\right.$ gure $5, b)$. Drilling rigs $\mathrm{TW}-100$ and Skytop Brewster N-75 A were applied for drilling wells \#101 and 110, respectively. Drilling was performed at rig rotation speed of 60-90 rpm with $2-12 \mathrm{t}$ force of drilling tool feed. Drilling water (specific weight of $1.12-1.16 \mathrm{~g} / \mathrm{cm}^{3}$, viscosity of $47 \mathrm{sec}, \mathrm{pH} 10-11.4$, water flow rate of 20$25 \mathrm{l} / \mathrm{s}$ )) was applied for well flushing-out and drilling tool cooling. Drilling intervals are represented by siltstones, mudstones and abrasive sandstones with up to $120 \mathrm{MPa}$ ultimate strength at uniaxial compression.
Test results were documented by the Act of commercial introduction of this drill bit. Overall driving of the drill bit after reconditioning was $1125 \mathrm{~m}$. Developed reconditioning technology enabled extension of drill bit working life by $112.5 \%$; after trials the wear of working elements, fitted with DIC, was equal to 10-20\%, and that of reconditioned watercourse was 1$2 \%$, i.e. it next reconditioning will be possible.

\section{Conclusions}

1. Basic technology of reconditioning drill bit steel body corresponds to bit classification by IADC code (watercourse channel) for drilling tools in service.

2. Technology of protective coating deposition by surfacing can be also applied for reconditioning other defective sections of working elements of drill bit steel bodies with protective coatings for uninterrupted drilling.

3. Study results can be used in mining industry of Ukraine and other countries.

1. Khorunov, V.F., Stefaniv, B.E., Sabadash, O.M. et al. (2012) Peculiarities of wear and criteria of repairability of drill bits with diamond-hard-alloy cutters. The Paton Welding J., 10, 39-43.

2. Khorunov, V.F., Stefaniv, B.E., Sabadash, O.M. et al. (2012) Peculiarities of technologies for repair of drill bits with diamond-hard alloy cutters. In: Problems of resource and service safety of structures, constructions and machines, 488-493. Kiev: PWI.

Received 14.05.2014 